\title{
Adaptive unfolded protein response promotes cell survival in rifampicin-treated L02 cells
}

\author{
WEIPING ZHANG ${ }^{1,2}$ and JIANMING XU ${ }^{1}$ \\ ${ }^{1}$ Department of Gastroenterology, The First Affiliated Hospital of Anhui Medical University, Key Laboratory of \\ Gastroenterology of Anhui Province; ${ }^{2}$ The First Affiliated Hospital of AUTCM, Hefei, Anhui 230022, P.R. China
}

Received July 26, 2016; Accepted January 23, 2018

DOI: $10.3892 /$ ijmm.2018.3438

\begin{abstract}
An important concept in drug-induced liver injury (DILI) is adaptation, which means the injury reverses with the continuation of the drug. The mechanism of adaption of drugs remains enigmatic, adaptive unfolded protein response (UPR) is possibly involved. We once observed adaptation phenomenon of rifampicin (RFP) in animal models, in this study, we investigate the effects of RFP on adaptive UPR in L02 cells, and after inhibiting UPR by using 4-phenylbutyrate (4-PBA), the change of cell viability and cell apoptosis in RFP-treated cells. We found that with the concentration of RFP increased and the treatment time was prolonged, the glucose-regulated protein 78 (GRP78), a hallmark of the UPR, was upregulated, and was dose- and time-dependent. RFP also activates the p-eukaryotic initiation factor $2 \alpha$ (eIF2 $\alpha$ ) protein expression. 4-PBA decreased GRP78 and p-eIF2 $\alpha$ protein expression levels. Moreover, FCA showed that cell apoptosis rate obviously increased, and MTT assay showed that cell survival rate obviously decreased, this indicates that after inhibiting the UPR, the cell damage increased, which shows that the UPR is an adaptation mechanism to protect cells against injury induced by RFP. This also proves that when the degree of UPR induced by RFP is relatively mild, adaptive UPR is helpful for cell survival.
\end{abstract}

\section{Introduction}

The endoplasmic reticulum (ER) plays a major role in folding, transportation, post-translational modification, and quality control of newly synthesized proteins (1). ER via expanding its protein folding ability adapts to increasing physiological demands for protein synthesis (2). Abnormalities such as the accumulation of unfolded proteins can interfere with the func-

Correspondence to: Professor Jianming $\mathrm{Xu}$, Department of Gastroenterology, The First Affiliated Hospital of Anhui Medical University, Key Laboratory of Gastroenterology of Anhui Province, Hefei, Anhui 230022, P.R. China

E-mail: xujm1017@163.com

Key words: unfolded protein response, rifampicin, 4-phenylbutyrate, L02 cells, and cell survival tion of ER, resulting in a dysfunctional situation described as ER stress (3). The ER stress response constitutes a series of cellular processes, the unfolded protein response (UPR), which aims to clear unfolded proteins and restore ER homeostasis, is a very important adaptive mechanism (4). Accumulation of unfolded proteins activates signaling pathways in the cytosol via the three stress sensor proteins: inositol-requiring kinase 1 (IRE1), PKR-like ER kinase (PERK) and activating transcription factor 6 (ATF6), which combine with glucose-regulated protein 78 (GRP78)/binding immunoglobulin protein (BIP) under normal circumstances. Activation of the UPR results in reduced protein synthesis and transcriptional activation of genes regulated by spliced $\mathrm{X}$-box binding protein-1S (XBP-1S), activating transcription factor 4 (ATF4), and ATF6. Consequently, UPR activation increases ER chaperone and folding enzyme concentrations to minimize misfolding and aggregation (5). Activation of the UPR is emerging as a common theme in protein-misfolding diseases, with relevant markers observed in patient tissue and mouse models (6). Several recent studies have shown that UPR may actually be beneficial to cells to fulfill specific requirements in unique cell types (7-10).

Rifampicin (RFP) is commonly used to treat tuberculosis worldwide, and it is well-known to induce drug-induced liver injury (DILI). RFP affects the expression of many of the cytochrome P450 drug metabolism genes, and alters the expression of many of the clinically relevant hepatic drug transporters, which may contribute to differences in drug exposure and possibly effect (11). In previous studies we found that RFP increased multidrug resistance protein 2 (Mrp2) and bile salt export pump (BSEP) expression in rats (12). RFP has been shown to cause hepatic toxicity in animal studies and clinical settings, but we also found that RFP could induce adaptive injury in mice (13). Mice were orally administered with a single dose of rifampicin $(200 \mathrm{mg} / \mathrm{kg})$, serum ALT, AST, ALP, total bilirubin (TB), conjugated bilirubin (CB), unconjugated bilirubin (UCB) and bile acids (BA) almost all started to rise from $0.5 \mathrm{~h}$, reached the peak at $6 \mathrm{~h}$ and then declined. The adaptation phenomenon plays an important role in understanding the toxic effects of drugs and clinical drug use. Adaptation is a situation in which the injury reverses with the continuation of the drug. A series of responses could mediate adaptation, including adaptive UPR induced by ER stress to regulate stress (14). 
In this study, we hypothesized that RFP would induce adaptive UPR in L02 cells. We used tunicamycin (TM) as control drug, and we used 4-phenylbutyrate (4-PBA) to inhibit UPR. TM is a nucleoside antibiotic, it prevents N-linked glycosylation and has both antibiotic and antiviral properties. It is known to induce ER stress. 4-PBA is a chemical chaperone that helps in protein folding and trafficking within the ER, so it alleviates ER stress and acts as an ER stress inhibitor $(15,16)$. To investigate this hypothesis, we examined many ER stress markers. To our knowledge, this is the first study focusing on RFP induced adaptive UPR.

\section{Materials and methods}

Drugs. RFP (Prod \#R3501), 4-PBA (Prod \#SML0309) and TM (Prod \#SML1287) were purchased from Sigma-Aldrich (St. Louis, MO, USA). RFP was dissolved in a $<0.1 \%$ DMSO (Sigma-Aldrich) solution, and the final concentration was $100 \mathrm{mg} / \mathrm{ml}$. 4-PBA was dissolved in sterile $\mathrm{ddH}_{2} \mathrm{O}$, and its final concentration was $1 \mathrm{M}$. The final concentration of TM was $5 \mathrm{mg} / \mathrm{ml}$ in DMSO.

Cell culture. Human normal hepatocyte cell line L02 was purchased from the Central Laboratory of the Xiangya School of Central South University (Hunan, China). Cells were cultivated in RPMI-1640 medium (HyClone, Logan, UT, USA) supplemented with $10 \%$ heat-inactivated fetal bovine serum (FBS), $100 \mathrm{U} / \mathrm{ml}$ penicillin, and $100 \mu \mathrm{g} / \mathrm{ml}$ streptomycin according to the manufacturer's instructions. Cells were maintained at $37^{\circ} \mathrm{C}$ in a humidified atmosphere with $5 \% \mathrm{CO}_{2}$. Half of the growth medium was changed each day. L02 cells at $60-70 \%$ confluency after the fourth passage were plated for the experiments.

MTT assay. The cell survival rate was determined using the conventional MTT assay. Briefly, L02 cells were seeded at a density of $5 \times 10^{3}$ cells/well in a 96-well plate, and the cells were incubated in serum-free and antibiotic-free medium for $24 \mathrm{~h}$ before stimulation. After $24 \mathrm{~h}$, the culture supernatant was replaced with fresh RPMI-1640 medium and added with different drugs of different concentration for 24 or $48 \mathrm{~h}$. Then the medium was removed, and the cells were washed twice with phosphate-buffered saline (PBS) buffer. Then $90 \mu \mathrm{l}$ of RPMI-1640 medium and $10 \mu$ of the MTT solution was added to each well, and the cells were incubated for $4 \mathrm{~h}$ at $37^{\circ} \mathrm{C}$. MTT (Sigma-Aldrich) was dissolved in PBS and filter sterilized at a concentration of $5 \mathrm{mg} / \mathrm{ml}$. Then, the medium was removed, and $150 \mu \mathrm{l}$ of DMSO was added to each well. The formazan dye crystals were solubilized on a shaker for $15 \mathrm{~min}$ at room temperature, and the absorbance at $570 \mathrm{~nm}$ of each well was measured using a microplate reader (Rayto, Shenzhen, China). The cell survival rate was determined by comparing the number of viable cells to that of the controls, which was defined as $100 \%$ cell viability.

Western blot analysis. After treatment, L02 cells were collected and lysed with RIPA lysis buffer: $50 \mathrm{mM}$ Tris-HCl (pH 8.0), 1\% Triton X-100, $150 \mathrm{mM} \mathrm{NaCl}, 10 \%$ SDS, $100 \mathrm{~m}$ methylenediaminetetraacetic acid (EDTA), 10\% NP-40 and $10 \%$ sodium deoxycholate. Equal amounts of protein for each sample were loaded with a known molecular weight marker onto 8 and $12 \%$ sodium dodecyl sulfate polyacrylamide gel electrophoresis (SDS-PAGE) gels. After gel electrophoresis, the proteins were transferred to polyvinylidene fluoride (PVDF) membranes for $150 \mathrm{~min}$ at $80 \mathrm{~V}$. After blocking the membranes in $5 \%$ nonfat milk for $1 \mathrm{~h}$ at room temperature, the membranes were washed with PBST (0.01 M PBS and 0.1\% Tween-20) three times, for 10 min each time. Then, the membranes were probed with the primary antibodies at a dilution of GRP78 $(1: 1,000)$, PERK (1:500), p-PERK (1:500), eukaryotic initiation factor $2 \alpha$ (eIF2 $\alpha)(1: 1,000)$, p-eIF2 $\alpha$ (1:1,000), ATF4 (1:1,000), CHOP (1:500), IRE1 (1:500), p-IRE1 (1:500), XBP-1U (1:500), XBP-1S $(1: 500)$, ATF6 $(1: 1,000)$ and $\alpha$-tubulin $(1: 4,000)$ in blocking buffer for $2 \mathrm{~h}$ at room temperature or incubated overnight at $4^{\circ} \mathrm{C}$. The antibodies against GRP78, ATF6, IRE1, p-IRE1, XBP-1U and CHOP were obtained from Abcam (Cambridge, UK). The antibodies against PERK, ATF4, eIF $2 \alpha$ and p-eIF $2 \alpha$ were from Cell Signaling Technology (Beverly, MA, USA). The antibody against p-PERK was from Santa Cruz Biotechnology, Inc. (Santa Cruz, CA, USA). The antibody against XBP-1S was from BioLegend (San Diego, CA, USA). The monoclonal anti- $\alpha$-tubulin antibody was purchased from Sigma-Aldrich. Then, the membrane was washed three times again, and subsequently, the membranes were incubated with a secondary antibody conjugated to horseradish peroxidase (rabbit or mouse, 1:4,000) for $1 \mathrm{~h}$ at room temperature and washed. The membranes were detected using the Gel Catcher 3400 (Shanghai, China), the ECL were purchased from Thermo Fisher Scientific (Waltham, MA, USA) and the data were analyzed with a gel documentation system from Clinx (Shanghai, China).

Immunofluorescence staining. L02 cells were cultured on the circular slide in a 24-well plate. After treatment, the slides were removed and were washed twice with PBS, fixed with $200 \mu \mathrm{l}$ $4 \%$ polyformaldehyde for $15 \mathrm{~min}$. The slides were washed with PBS three times, for 5 min each time, then the slides were treated with $200 \mu \mathrm{l}$ of $0.1 \%$ Triton X-100 for $15 \mathrm{~min}$, blocked with $200 \mu \mathrm{l} 5 \% \mathrm{BSA}$ for $30 \mathrm{~min}$. After that, the slides were incubated with the specific primary antibodies at a dilution of 1:50 in PBS buffer, followed by staining with the secondary antibodies at a dilution of 1:200 in PBS buffer in dark. DAPI with concentration of $1 \mu \mathrm{g} / \mathrm{ml}$ was added to each slide for $10 \mathrm{~min}$. After that, the slides were washed and mounted with $80 \%$ glycerol. The slides were viewed with Olympus IX73P2F (SN: 2J44787). In each group, immunofluorescence images were captured with the same light exposure times.

Flow cytometric assay (FCA). After treatment, the L02 cells were subjected to Annexin V-FITC binding and propidium iodide (PI) staining according to the manufacturer's protocol as follows. Samples were collected after trypsinization, and the cells were washed twice with cold PBS buffer. Then, $400 \mu 1$ of Annexin $\mathrm{V}$ binding buffer was added to each flow tube, and then $5 \mu 1$ of Annexin V-FITC was added to the culture on ice for $15 \mathrm{~min}$ in the dark. After that, $10 \mu \mathrm{l}$ propidium iodide (PI) was added to the culture on ice for $5 \mathrm{~min}$ in the dark. Then, the samples were analyzed by flow cytometer within $1 \mathrm{~h}$. The model of the flow cytometer was BD FACSCanto ${ }^{\mathrm{TM}}$ II (SN:V33896301389; BD Biosciences, San Jose, CA, USA). 

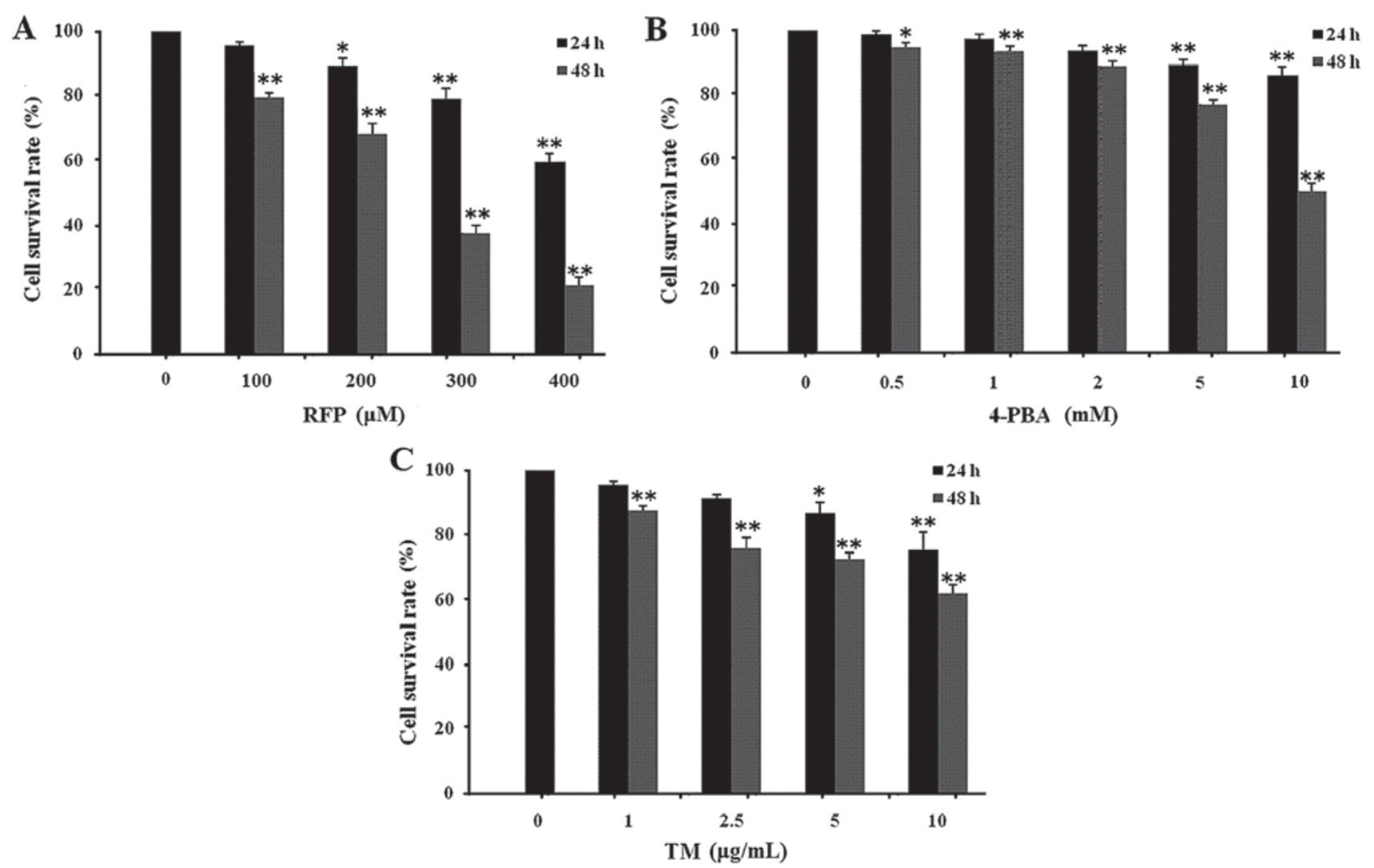

Figure 1. The impact of (A) rifampicin (RFP), (B) 4-phenylbutyrate (4-PBA), and (C) tunicamycin (TM) on the cell survival rate of L02 cells. (A) The cell survival rate of L02 cells exposed to different concentrations (100, 200, 300 and $400 \mu \mathrm{M})$ at different times (24 and $48 \mathrm{~h})$ of RFP. The cell survival rates were measured using an MTT assay, and the results showed that with the increase in the concentration and treatment time of RFP, the L02 cell survival rate decreased gradually. A similar trend was observed in (B) 4-PBA-treated L02 cells and (C) TM-treated cells. The experiment was repeated three times, and the data represent the mean \pm SEM. ${ }^{*} p<0.05$ and ${ }^{* *} \mathrm{p}<0.01$ compared with the control.

Cells negative for both Annexin V-FITC and PI staining were considered live cells. PI-positive cells were considered to be necrotic. Annexin V-FITC positive cells were considered to be in early apoptosis, and cells positive for both Annexin V-FITC and PI were considered to be in late apoptosis. The total number of apoptotic cells was defined as the sum of the early apoptotic and late apoptotic cells. All experiments were repeated at least three times.

Statistical analysis. Statistical analyses were performed using the Statistical Package for the Social Science (SPSS version 12.0; SPSS, Chicago, IL, USA) software. Experimental results are presented as the mean \pm standard error of the mean (SEM) derived from three independent experiments. Comparisons between groups were made using a one-way analysis of variance (ANOVA) followed by the least-significant difference (LSD) test. Probability values $<0.05$ were considered significant.

\section{Results}

Effect of RFP, 4-PBA, and TM on the survival rate of $L 02$ cells. In order to observe the cell toxicity of these three drugs, L02 cells were treated with RFP at different concentration (100, 200, 300 and $400 \mu \mathrm{M}), 4-\mathrm{PBA}$ at different concentration (0.5, $1,2,5$ and $10 \mathrm{mM}), \mathrm{TM}$ at different concentration $(1,2.5,5$ and $10 \mu \mathrm{g} / \mathrm{ml})$, both at different time-points (24 and $48 \mathrm{~h}$ ). The results of the MTT assay demonstrated that with the increase in the concentration of these three drugs and treatment time, the L02 cell survival rate decreased gradually, thus showing a doseand time-dependent effect (Fig. 1). When the concentration of RFP was higher than $100 \mu \mathrm{M}$, the concentration of 4-PBA was higher than $2 \mathrm{mM}$, and the concentration of TM was higher than $2.5 \mu \mathrm{g} / \mathrm{ml}$, the cell survival rate was significantly inhibited. The $\mathrm{IC}_{50}$ value for RFP of $24 \mathrm{~h}$ was $\sim 548.91 \mu \mathrm{M}$ and at $48 \mathrm{~h}$ was $\sim 234.96 \mu \mathrm{M}$. Refering to previous studies $(17,18)$ we ascertain RFP of $100 \mu \mathrm{M}, 4-\mathrm{PBA}$ of $2 \mathrm{mM}$, and TM of $2.5 \mu \mathrm{g} / \mathrm{ml}$ as the test concentrations in the following experiment.

RFP effect on GRP78 protein expression in L02 cells. Because GRP78 plays an important role in initiating the adaptive ER stress and inhibiting apoptotic ER stress (19), we first observed the change in the protein expression of GRP78 in RFP-treated L02 cells. Western blot analysis showed that RFP treatment upregulated the expression of GRP78 in a dose-dependent and time-dependent manner. As shown in Fig. 2A, when incubated with increasing concentrations of RFP ranging from 25 to $100 \mu \mathrm{M}$ for $6 \mathrm{~h}, \mathrm{~L} 02$ cells showed a dose-dependent induction of GRP78, with $100 \mu \mathrm{M}$ RFP GRP78 protein expression was significantly elevated $(\mathrm{p}<0.05)$ and $\mathrm{TM}$ was obviously higher than $100 \mu \mathrm{M}$ RFP $(\mathrm{p}<0.01)$. As shown in Fig. 2B, $100 \mu \mathrm{M}$ RFP induced a significant increase in the protein expression of GRP78 beginning at $6 \mathrm{~h}(\mathrm{p}<0.05)$ and continued until $24 \mathrm{~h}$ $(\mathrm{p}<0.01)$. 

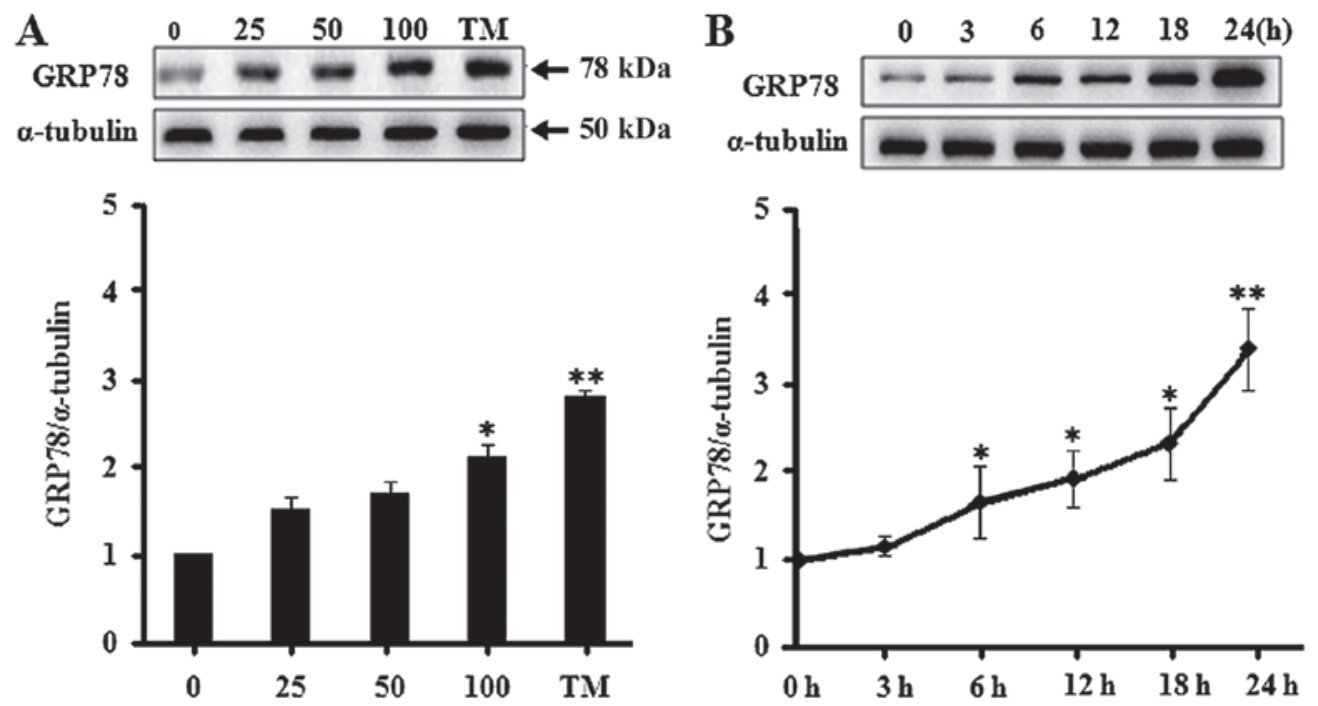

Figure 2. The impact of rifampicin (RFP) on the protein expression of glucose-regulated protein 78 (GRP78) in L02 cells. (A) Cells were treated with 25-100 $\mu \mathrm{M}$ RFP or tunicamycin (TM) $(2.5 \mu \mathrm{g} / \mathrm{ml})$ for $6 \mathrm{~h}$. Western blot analysis showed that RFP upregulated GRP78 protein expression at $100 \mu \mathrm{M}$. (B) Cells were treated with $100 \mu \mathrm{M}$ rifampicin for the indicated periods of time, and RFP significantly upregulated GRP78 protein expression at 6, 12, 18 and $24 \mathrm{~h}$. The experiment was repeated three times, and the protein expression was normalized relative to the control cells, in which protein expression was deemed to be 1. The data are presente as the mean \pm SEM. ${ }^{*} \mathrm{p}<0.05$ and ${ }^{* *} \mathrm{p}<0.01$ compared with the control.

RFP effect on the IRE1 $\alpha$-XBPI, PERK and ATF6 pathways in LO2 cells. As known, the UPR includes three pathways, and we observed the effect of RFP on IRE1 $\alpha$ pathway, PERK pathway, and ATF6 pathway protein expression. As shown in Fig. 3A, cells were treated with RFP and TM for $6 \mathrm{~h}$, there was a similar trend of p-eIf $2 \alpha$ protein expression with GRP78. RFP of $50 \mu \mathrm{M}$ induced p-eIf $2 \alpha$ protein expression $(\mathrm{p}<0.05)$ and $100 \mu \mathrm{M}$ RFP was stronger $(\mathrm{p}<0.01)$, while TM still had a more powerful activation. The other ER stress protein expression did not change significantly. Next we observed RFP and TM treatment for $24 \mathrm{~h}$ (Fig. 3B) $100 \mu \mathrm{M}$ RFP still increased GRP78, p-elf2 $\alpha$ protein expression, while TM increased GRP78, p-eIf2 $\alpha$, ATF4, XBP-1U and XBP-1S protein expression.

4-PBA inhibits ER stress protein expression in RFP-treated LO2 cells. To determine whether 4-PBA could inhibit RFP and TM induced ER stress protein expression, L02 cells were treated with $2 \mathrm{mM} 4$-PBA for $2 \mathrm{~h}$, followed by $100 \mu \mathrm{M}$ RFP and TM for $24 \mathrm{~h}$. 4-PBA could cut down the expression level of GRP78 protein (all p<0.05) (Fig. 4). RFP had no activated effect on IRE1 $\alpha$, p-IRE1 $\alpha$, XBP-1U, XBP-1S protein expression, TM activated XBP-1U, XBP1-1S protein expression, but the value of XBP-1S/XBP-1U had no difference between the other groups. 4-PBA could inhibit expression of XBP-1S protein obviously. After given RFP, p-eIf $2 \alpha /$ If $2 \alpha$ level was icreased $(p<0.05), 4-$ PBA could cut down the level of p-eIf $2 \alpha /$ eIf $2 \alpha(p<0.05)$. TM increased p-eIf $2 \alpha /$ eIf $2 \alpha$ level and ATF4 protein expression level (all p<0.05), 4-PBA could inhibit expression of these two proteins (all $\mathrm{p}<0.05$ ). RFP and TM had no effect on ATF6 protein expression.

4-PBA effect on protein localization of GRP78 and p-eIf $2 \alpha$ in RFP-treated L02 cells. The expression of GRP78 and p-eIf $2 \alpha$ protein was minor in the control group, and the localization was mainly in the cytoplasm (Fig. 5). RFP treatment showed increased staining in the cytoplasm, and after 4-PBA treatment showed decreased staining in the cytoplasm.

4-PBA effect on cell apoptosis survival and cell survival in RFP-treated LO2 cells. We determined 4-PBA effect on RFP-treated cells by using FCA and MTT assay. We found that incubation of L02 cells with $100 \mu \mathrm{M}$ RFP and TM for $24 \mathrm{~h}$ had no obvious influence on the number of apoptotic cells compared to the control (Fig. 6A). After treatment with 4-PBA, the number of apoptotic cells significantly increased $(\mathrm{p}<0.01)$. Our MTT assay showed that 4-PBA decreased cell survival rate both in RFP treatment group and TM treatment group (all p<0.01) (Fig. 6B).

\section{Discussion}

DILI is often responsible for boxed warnings, drug nonapproval or drug withdrawal, even in acute liver failure (ALF) (20). Many drugs cause hepatotoxicity, including over-the-counter (OTC) drugs (21), herbs and dietary supplements (22-24). The symptoms of DILI range from mildly elevated liver enzymes to severe hepatic damage like ALF. Mortality from DILI in individuals with pre-existing liver disease or concomitant severe skin reactions is significantly higher than patients without (25). Risk factors in DILI including drug factors such as threshold dose and lipophilicity, reactive metabolites and oxidative stress, mitochondrial hazards, hepatobiliary transporter inhibition, and host factors such as age, gender, race, genetic variants, nutrition, alcohol, smoking, underlying liver disease, comorbidities, drug-drug interactions and gut flora $(26,27)$.

Antimicrobials, including antibacterial agents and antituberculosis (anti-TB) agents, have been found to be the most common drugs leading to DILI (28). Anti-TB drugs, including RFP, isoniazid (INH) and pyrazinamide (PZA) probably carry some of the highest DILI risk of any medication, but are 

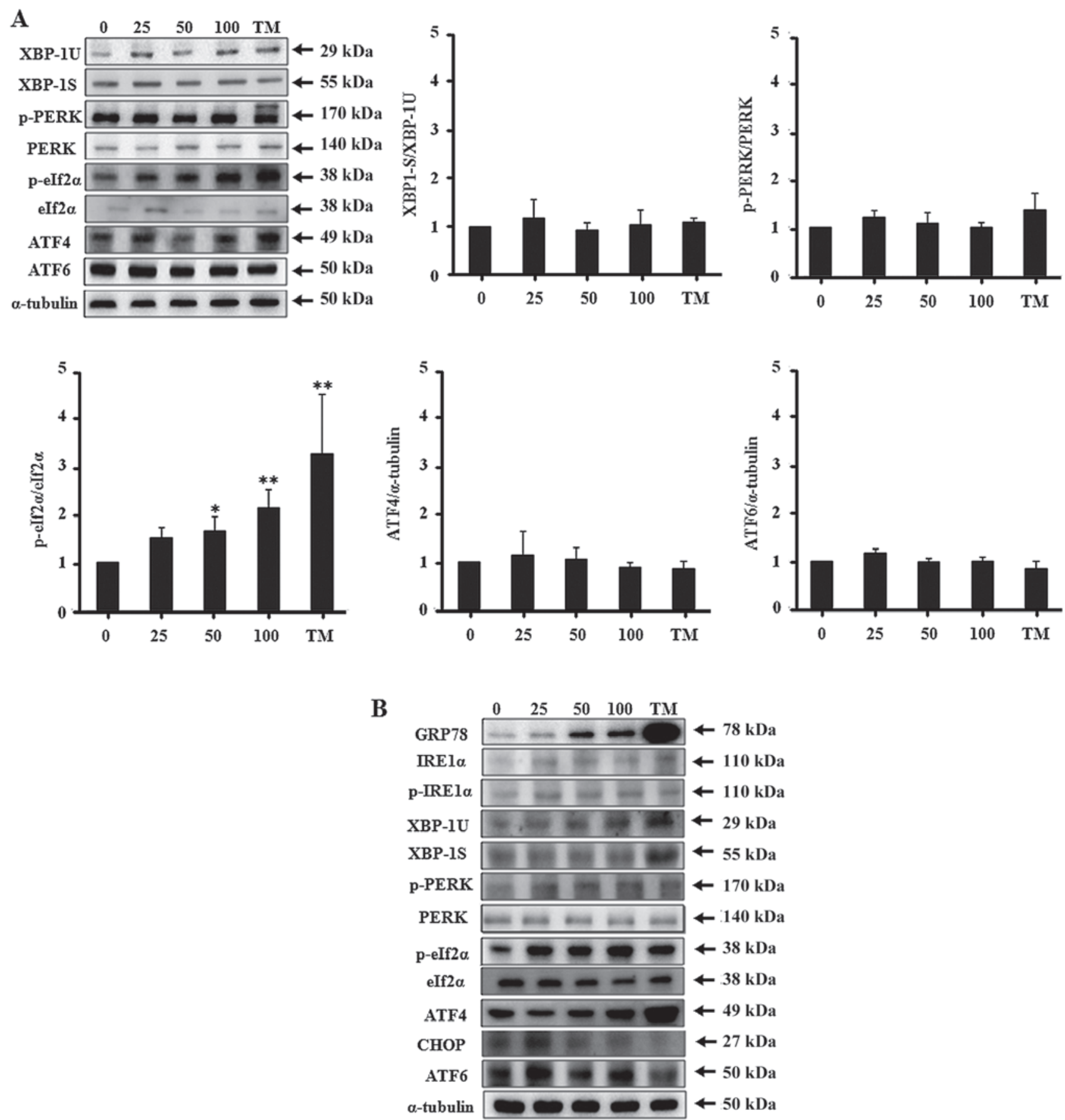

Figure 3. The impact of rifampicin (RFP) treatment for (A) $6 \mathrm{~h}$ and (B) $24 \mathrm{~h}$ on IRE1 $\alpha$ pathway, PKR-like ER kinase (PERK) pathway, and ATF6 pathway in L02 cells. (A) Cells were treated with 25-100 $\mu \mathrm{M}$ RFP or tunicamycin (TM) $(2.5 \mu \mathrm{g} / \mathrm{ml})$ for 6 h, western blot analysis showed that from $50 \mu \mathrm{M}$ RFP started to show an upregulated trend of p-eukaryotic initiation factor $2 \alpha$ (eIf $2 \alpha$ ) protein expression. The experiment was repeated three times, protein expression was relative to control cells, in which protein expression was deemed to be 1 . Data are presented as mean \pm SEM. ${ }^{*}<<0.05$ and ${ }^{* *} \mathrm{p}<0.01$ compared with the control. (B) Western blot analysis showed that glucose-regulated protein 78 (GRP78) and p-eIf $2 \alpha$ protein expression were elevated in RFP treatment group, while GRP78, p-eIf2 $\alpha$, ATF4, X-box binding protein-1U (XBP-1U) and XBP-1S protein expression were elevated in TM treatment group.

less commonly prescribed compared to amoxicillin-clavulanate (29). Anti-TB drug-induced liver injury is a major cause of DILI in India and much of the developing world (30). RFP may occasionally disturb the bilirubin uptake in a dose-dependent manner, resulting in jaundice or unconjugated hyperbilirubinemia without hepatocellular damage (31). RFP occasionally cause hepatocellular injury has also been reported. The latency injury of RFP is 0-3 month. A unique feature of anti-TB drugs is the adaptation or tolerance to the drugs, which means the patients present elevation of transaminases and/or bilirubin, without any clinical symptoms, which resolves with continuation of the drugs (30). Exposure to specific drugs may trigger physiologic adaptive responses. The activation of survival genes, including those that regulate antiinflammatory, antioxidant, and antiapoptotic pathways, may alleviate toxin-related harmful responses. Such injury may also stimulate protective adaptation and hepatocyte proliferation (31). Some evidence in human suggests that this adaptation response last for months 

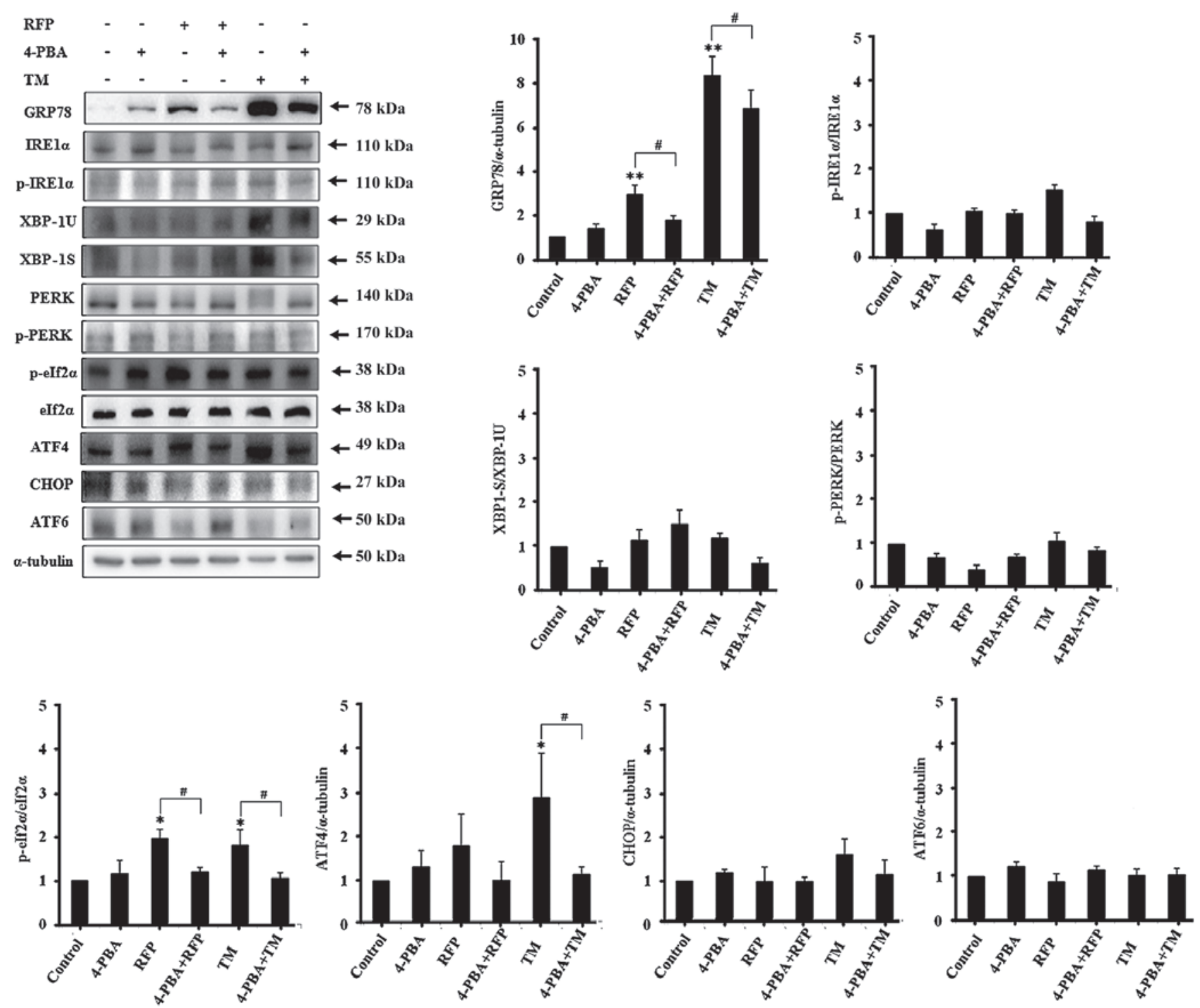

Figure 4. 4-Phenylbutyrate (4-PBA) inhibits glucose-regulated protein 78 (GRP78) and p-eukaryotic initiation factor $2 \alpha$ (eIf $2 \alpha$ ) protein expression in rifampicin (RFP) treated L02 cells. Cells were treated with $2 \mathrm{mM} 4$-PBA for $2 \mathrm{~h}$, followed by $100 \mu \mathrm{M}$ RFP or tunicamycin (TM) $(2.5 \mu \mathrm{g} / \mathrm{ml})$ for $24 \mathrm{~h}$. Western blot analysis showed that RFP upregulated GRP78 and p-eIf $2 \alpha$ protein expression. 4-PBA could cut down the expression level of GRP78 and p-eIf $2 \alpha$ protein induced by RFP. The experiment was repeated three times, protein expression was relative to control cells, in which protein expression was deemed to be 1 . Data are presented as mean \pm SEM. ${ }^{*} \mathrm{p}<0.05$ and ${ }^{* *} \mathrm{p}<0.01$ compared with the control; ${ }^{*} \mathrm{P}<0.05$ compared between the groups.

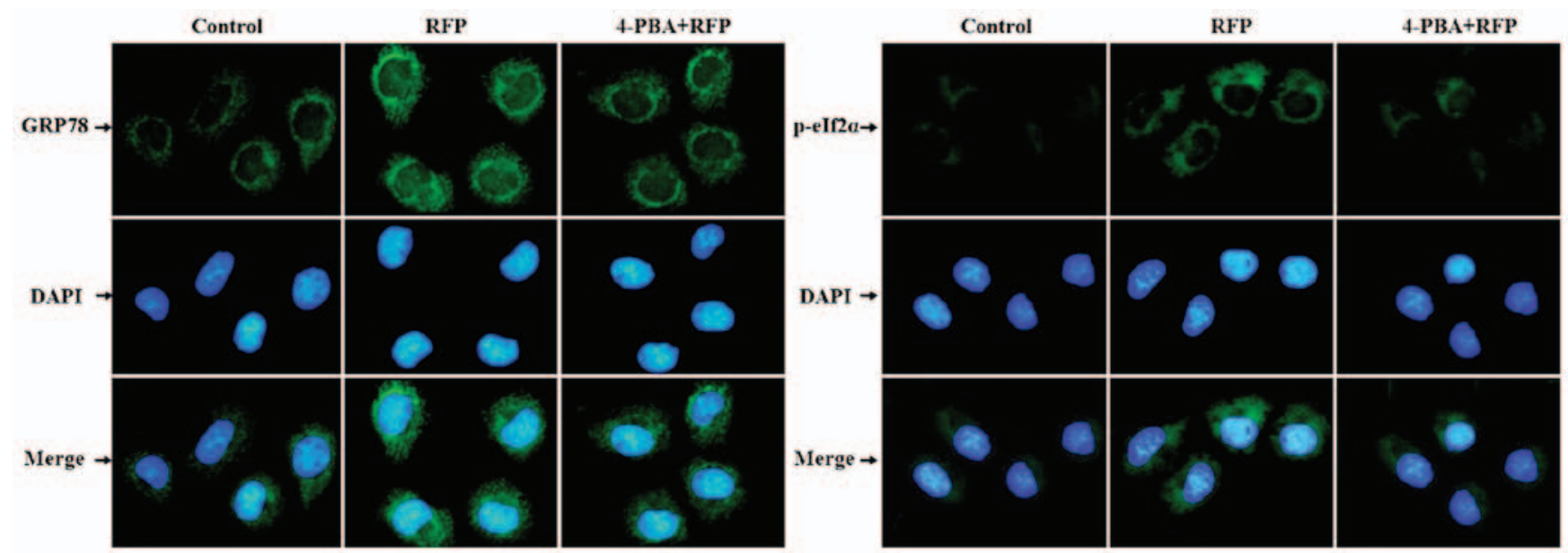

Figure 5. Immunostaining of glucose-regulated protein 78 (GRP78) and p-eukaryotic initiation factor $2 \alpha$ (eIf2 $\alpha$ ) (green) in L02 cells (x200). Cells were treated with $2 \mathrm{mM}$ 4-phenylbutyrate (4-PBA) for $2 \mathrm{~h}$, followed by $100 \mu \mathrm{M}$ rifampicin (RFP) for $24 \mathrm{~h}$. The nuclei were counterstained with DAPI (blue), the final merged image is a representative of three independent experiments. 
A

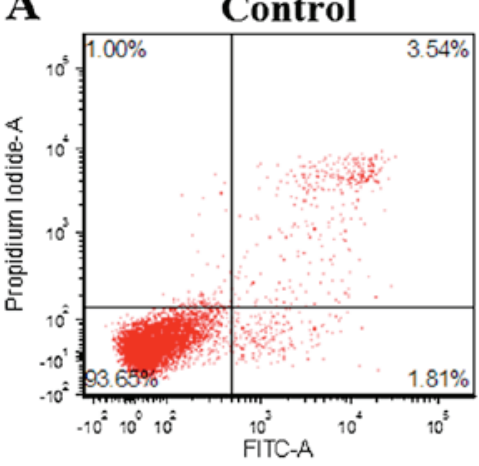

4-PBA+RFP
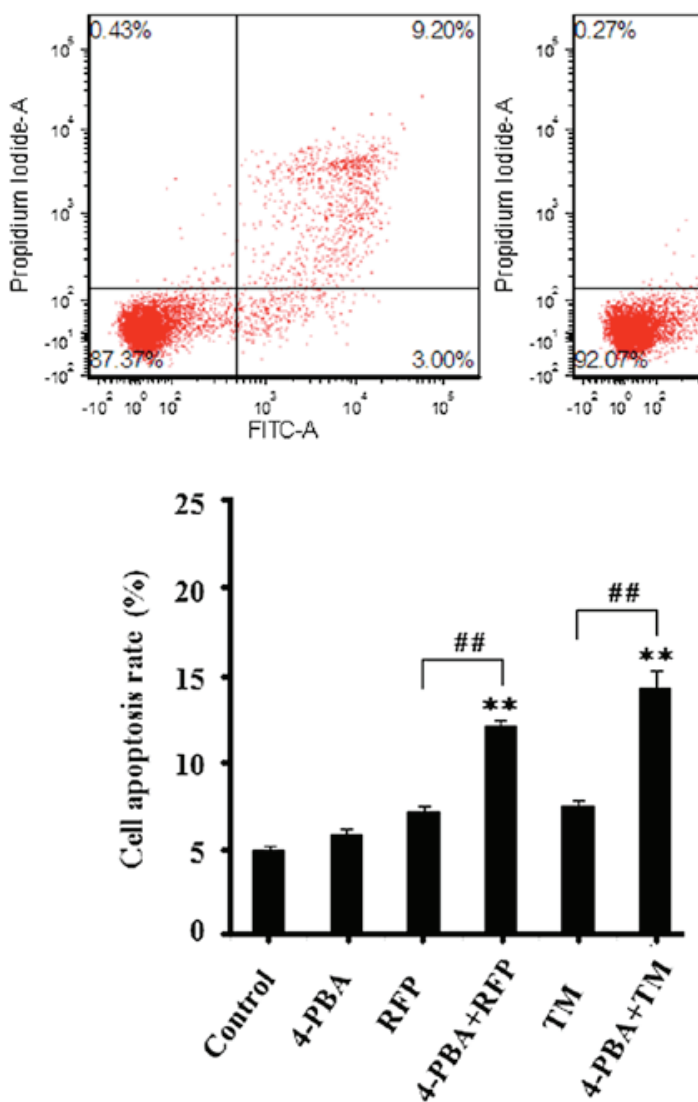

4-PBA

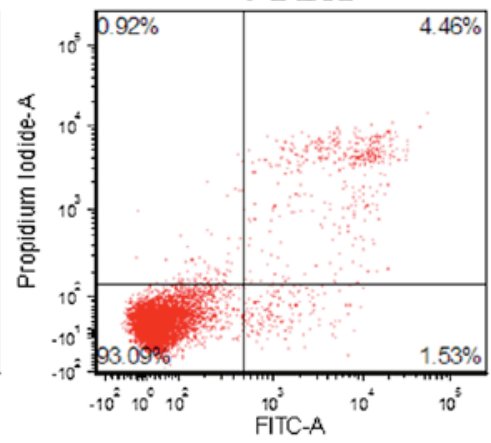

TM

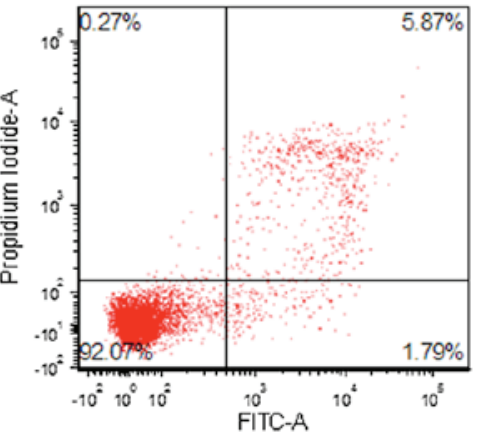

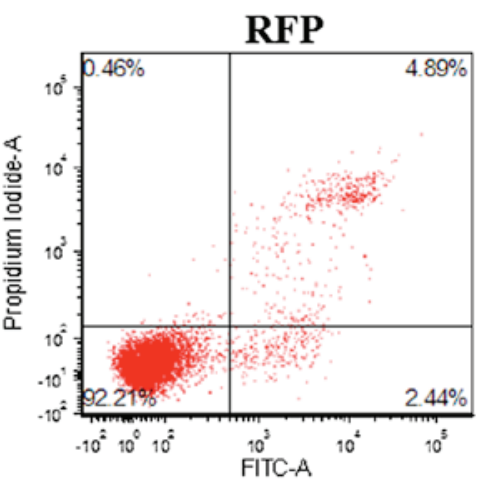

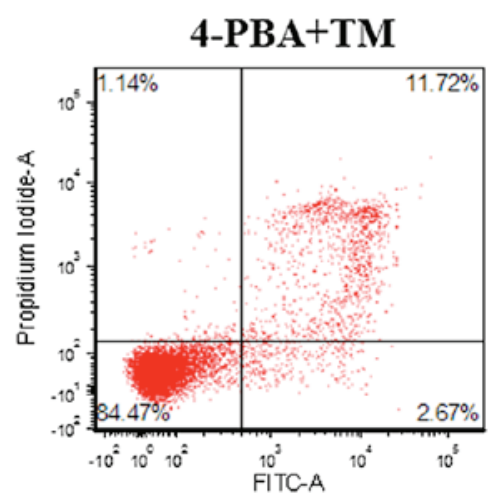

B

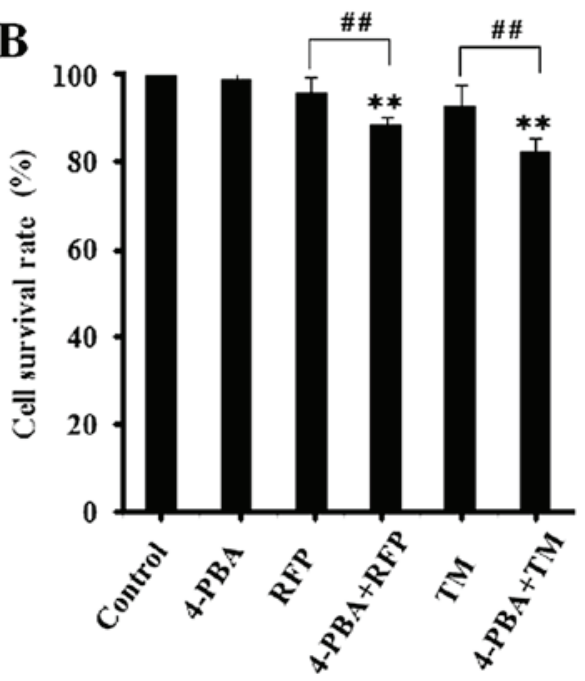

Figure 6. 4-Phenylbutyrate (4-PBA) increases rifampicin (RFP) induced L02 cells apoptosis and decreases cell viability. Cells were treated with $2 \mathrm{mM} 4$-PBA for $2 \mathrm{~h}$, followed by $100 \mu \mathrm{M}$ RFP or tunicamycin (TM) $(2.5 \mu \mathrm{g} / \mathrm{ml})$ for $24 \mathrm{~h}$. (A) FCA showed that RFP cotreatment with 4-PBA increased apoptosis obviously. (B) MTT assay showed that RFP cotreatment with 4-PBA decreased cell viability obviously. The same trend was found in TM treatment group. Data are present as mean \pm SEM of three independent experiments. ${ }^{* *} \mathrm{p}<0.01$ compared with the control; ${ }^{\# \#} \mathrm{p}<0.01$ compared between the groups.

after a mild DILI occurred (32). Thus, awareness of the phenomenon of adaptation is critical in tuberculosis treatment, helps to avoid unnecessary drug withdrawal so as to prevent the deterioration of the condition.

Recent studies suggested that ER stress plays an important role in DILI, in addition to oxidative stress, mitochondrial dysfunction, and many other mechanisms (33). ER stress activates an adaptive response termed the UPR to restore the ER homeostasis. If restored the ER homeostasis is unsuccessful, the UPR initiates a proapoptotic response to clear dysfunctional cells (34). The UPR has three main function: reduction in protein translation to decrease ER protein load; increase the ability of protein folding and export capacity of the ER, and activation of ER-associated degradation (ERAD) (9). An adaptive UPR helps to maintain ER homeostasis, it also regulates dynamic interactions between ER and mitochondria and autophagy to support ER function (35). Activation of the UPR promotes axonal regeneration after peripheral nerve injury (36). Inhibition of the UPR by hypoxia reduces ER-to-Golgi protein trafficking and increases cell death in mouse $\beta$ cells (37). The ability to maintain the adaptive UPR in islets may protect obese mice against diabetes development (38).

In this study, we found that RFP upregulated GRP78 expression in a dose-and time-dependent manner, indicating that RFP was a GRP78 inducer. GRP78 belongs to the heat shock 70 


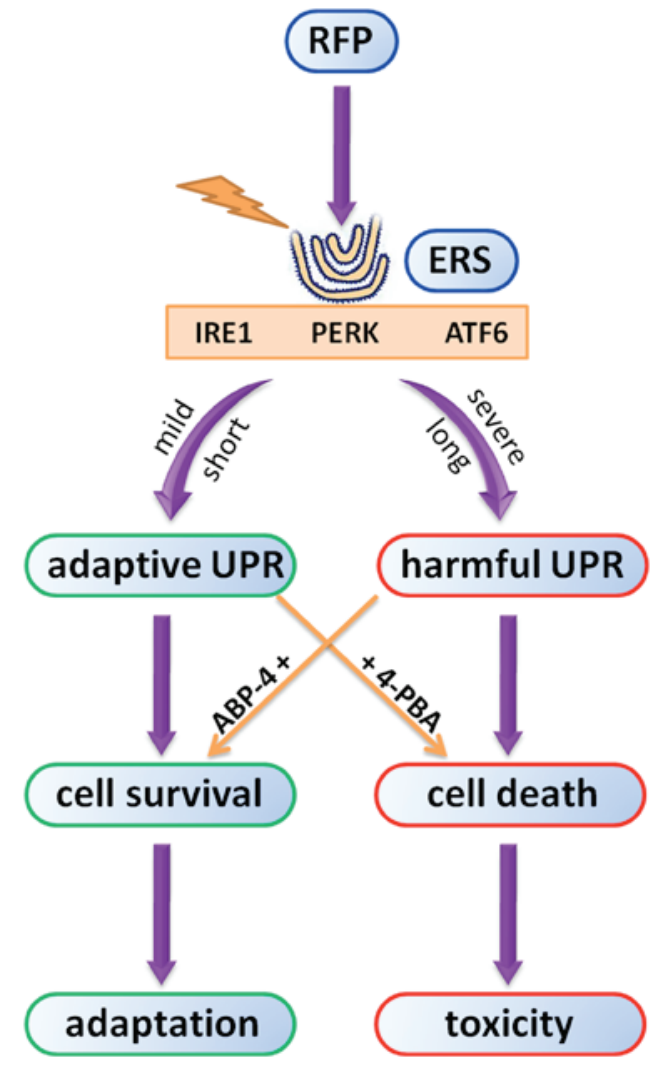

Figure 7. Possible schematic model of how unfolded protein response (UPR) affects rifampicin (RFP)-induced hepatotoxic effects. When the degree of endoplasmic reticulum (ER) stress induced by RFP is relatively mild and the duration is short, adaptive UPR was actived to promote cell survival. At this time 4-phenylbutyrate (4-PBA) inhibits the UPR increased cell death instead. If the degree of ER stress induced by RFP is relatively severe and the duration is long, harmful or injurious UPR was actived leading to cell death At this point 4-PBA inhibition of UPR is good for cell survival. Cell survival leads to adaption of the drug, and cell death contributed to the drug toxicity.

protein (HSP70) family, during ER stress GRP78 binds the unfolded proteins releasing the three UPR sensors (39). Due to its multiple functional roles in protein folding, controlling the activation of transmembrane ER stress sensors, and ER calcium binding, GRP78 is a central regulator of ER homeostasis. Study shows that GRP78 is required for cell proliferation (40). Overexpression of GRP78 enhanced cell proliferation in chondrocyte development, and inhibited ER stress-mediated apoptosis (41). GRP78 heterozygosity attenuates diet-induced obesity and insulin resistance by promoting adaptive UPR (42). Liver GRP78 was required for neonatal survival, and a loss of GRP78 in the adult liver greater than 50\% caused dilation of the ER compartment and an ER stress response, with the increase of apoptosis at the same time. 4-PBA could alleviate these disorders. Therefore, it is convincing that GRP78 is an important factor in adaptive UPR and as a protection.

The UPR is initiated by activation of specialized sensors including IRE1 $\alpha$, PERK and ATF6. The contribution of each pathway to the disease process is complex and highly dependent on the disease-triggering mechanisms and the cell type affected (36).IREl $\alpha$ catalyzes the splicing of the mRNA encoding for XBP1, resulting in the production of an active transcription factor termed XBP1s, which is essential for the expression of genes involved in protein secretion, folding and ERAD. PERK phosphorylation of eIF $2 \alpha$ represses global protein synthesis, lowering influx of nascent polypeptides into the stressed ER, coincident with preferential translation of ATF4. In cultured cells, ATF4 induces transcriptional expression of genes directed by the PERK arm of the UPR, including genes involved in resistance to oxidative stress, amino acid metabolism, and the proapoptotic transcription factor CHOP (GADD153/DDIT3) (43). ATF6 is also important for cell growth and ER stress-mediated apoptosis. We investigated the effects of RFP on the protein expression of the three pathways. We found that RFP had no significant effect on the protein expression except for p-eIF $2 \alpha$. p-eIF $2 \alpha$ is primarily a stress signal, it evokes adaptive or apoptotic responses depending on its cellular location, coincident signaling activities, changes in gene expression, and inter-protein interactions (44). p-eIF2 $\alpha$ reduces general translation initiation, but for select transcripts such as ATF4, it will facilitate the preferential translation (45). p-eIF $2 \alpha$ is more relevant to acute toxicity, the activation time start early (46). p-eIF $2 \alpha$ triggers an adaptation process in glucose-deficient cells, contributing to cell survival (47). Other studies also shown that p-eIF2 $\alpha$ plays a cytoprotective role and contribute to cell survival (48-50).

TM is generally used to induce ER stress experimentally as it is an N-linked glycosylation inhibitor. TM significantly increased the expression of XBP-1S, p-eIF2 $\alpha$ and GRP78 in the cerebral cortex and cerebellum of mouse (51). TM increased the expression of p-eIF2 $\alpha$ and ATF4 in neuroblastoma cells (52). GRP78 was elevated in TM-treated HepG2 and SMMC-7721 cells (53). GRP78, p-PERK, XBP-1S, p-IRE1 were activated by TM in skeletal muscle cells (54). In this study, we found that TM upregulated GRP78, XBP-1U, XBP-1S, p-eIF2 $\alpha$ and ATF4, suggested that the ER stress is also widely activated.

4-PBA, an aromatic fatty acid analog, is used to treat urea cycle disorders. Moreover, 4-PBA is also a chemical chaperone and histone deacetylase inhibitor. 4-PBA significantly reduced GRP78, ATF4 in a rat unilateral ureteral obstruction (UUO) model (55). 4-PBA reduced levels of both p-eIF $2 \alpha$ and CHOP, reduced apoptosis in mice of liver ischemiareperfusioninjury (56). 4-PBA reduced p-eIF2 $\alpha$ expression in mouse livers exposed to PFOA (57). In this study, we found that 4-PBA reduced levels of both GRP78 and p-eIF2 $\alpha$ induced by RFP, reduced levels of both GRP78, p-eIF2 $\alpha$ and ATF4 induced by TM, along with the increased cell apoptosis rate and the decreased cell survival rate, this shows that after the inhibition of UPR, cell damage is more serious. This proves that when the degree of UPR induced by RFP is relatively mild, adaptive UPR is helpful for cell survival which is associated with upregulated expression of GRP78 and p-eIF $2 \alpha$. We speculate that microscopic changes of cells may appear early after given RFP, the cells reduce damage by some adaptive responses, including adaptive UPR, which contribute to cell survival and the adaption of the drug (Fig. 7). Future animal studies may further verify this mechanism.

\section{Acknowledgements}

Not applicable.

\section{Funding}

We are grateful for funding support by the National Natural Science Foundation of China, grant no. 81370529. 


\section{Availability of data and material}

The datasets used and/or analyzed during the current study are available from the corresponding author on reasonable request.

\section{Authors' contributions}

JX designed the research, WZ performed the research, and was a major contributor in writing the manuscript. All authors read and approved the final manuscript.

\section{Ethics approval and consent to participate}

Not applicable.

\section{Consent for publication}

Not applicable.

\section{Competing interests}

The authors declare that they have no competing interests.

\section{References}

1. Perri ER, Thomas CJ, Parakh S, Spencer DM and Atkin JD The unfolded protein response and the role of protein disulfide isomerase in neurodegeneration. Front Cell Dev Biol 3: 80, 2016.

2. Mollereau B, Manié S and Napoletano F: Getting the better of ER stress. J Cell Commun Signal 8: 311-321, 2014.

3. Takayanagi S, Fukuda R, Takeuchi Y, Tsukada S and Yoshida K: Gene regulatory network of unfolded protein response genes in endoplasmic reticulum stress. Cell Stress Chaperones 18: 11-23, 2013.

4. Sano R and Reed JC: ER stress-induced cell death mechanisms. Biochim Biophys Acta 1833: 3460-3470, 2013.

5. Lindquist SL and Kelly JW: Chemical and biological approaches for adapting proteostasis to ameliorate protein misfolding and aggregation diseases: Progress and prognosis. Cold Spring Harb Perspect Biol 3: a004507, 2011.

6. Smith HL and Mallucci GR: The unfolded protein response: Mechanisms and therapy of neurodegeneration. Brain 139: 2113-2121, 2016

7. Hassler JR, Scheuner DL, Wang S, Han J, Kodali VK, Li P, Nguyen J, George JS, Davis C, Wu SP, et al: The IRE1 $\alpha / \mathrm{XBP} 1$ s pathway is essential for the glucose response and protection of $\beta$ cells. PLoS Biol 13: e1002277, 2015.

8. Lugea A, Waldron RT and Pandol SJ: Pancreatic adaptive responses in alcohol abuse: Role of the unfolded protein response. Pancreatology 15 (Suppl 4): S1-S5, 2015.

9. Lugea A, Tischler D, Nguyen J, Gong J, Gukovsky I, French SW, Gorelick FS and Pandol SJ: Adaptive unfolded protein response attenuates alcohol-induced pancreatic damage. Gastroenterology 140: 987-997, 2011.

10. Cano M, Wang L, Wan J, Barnett BP, Ebrahimi K, Qian J and Handa JT: Oxidative stress induces mitochondrial dysfunction and a protective unfolded protein response in RPE cells. Free Radic Biol Med 69: 1-14, 2014.

11. Benson EA, Eadon MT, Desta Z, Liu Y, Lin H, Burgess KS, Segar MW, Gaedigk A and Skaar TC: Rifampin regulation of drug transporters gene expression and the association of MicroRNAs in human hepatocytes. Front Pharmacol 7: 111, 2016.

12. Wang W, Ren X, Cai Y, Chen L, Zhang W and Xu J: Rifampicin induces bicarbonate-rich choleresis in rats: Involvement of anion exchanger 2. Dig Dis Sci 61: 126-136, 2016.

13. Chen X, Zhang C, Wang H, Xu J, Duan ZH, Zhang Y, Yu T, Wei W, Xu DX and Xu JM: Altered integrity and decreased expression of hepatocyte tight junctions in rifampicininduced cholestasis in mice. Toxicol Appl Pharmacol 240: 26-36, 2009

14. Verma S and Kaplowitz N: Diagnosis, management and prevention of drug-induced liver injury. Gut 58: 1555-1564, 2009.
15. Carlisle RE, Brimble E, Werner KE, Cruz GL, Ask K, Ingram AJ and Dickhout JG: 4-Phenylbutyrate inhibits tunicamycininduced acute kidney injury via CHOP/GADD153 repression. PLoS One 9: e84663, 2014.

16. Kolb PS, Ayaub EA, Zhou W, Yum V, Dickhout JG and Ask K: The therapeutic effects of 4-phenylbutyric acid in maintaining proteostasis. Int J Biochem Cell Biol 61: 45-52, 2015.

17. Hong D, Li LF, Gao HC, Wang X, Li CC, Luo Y, Bai YP and Zhang GG: High-density lipoprotein prevents endoplasmic reticulum stress-induced downregulation of liver LOX-1 expression. PLoS One 10: e0124285, 2015.

18. Rahman SM, Qadri I, Janssen RC and Friedman JE: Fenofibrate and PBA prevent fatty acid-induced loss of adiponectin receptor and pAMPK in human hepatoma cells and in hepatitis $\mathrm{C}$ virus-induced steatosis. J Lipid Res 50: 2193-2202, 2009.

19. Wang L, Tang W, Jiang T, Lu P, Li Y, Sun A, Shen Y, Chen Y, Wang H, Zong Z, et al: Endoplasmic reticulum stress is involved in the neuroprotective effect of propofol. Neurochem Res 39: 1741-1752, 2014.

20. Douros A, Bronder E, Andersohn F, Klimpel A, Thomae M, Sarganas G, Kreutz R and Garbe E: Drug-induced liver injury: Results from the hospital-based Berlin Case-Control Surveillance Study. Br J Clin Pharmacol 79: 988-999, 2015.

21. Takeda K, Oda M, Okada T, Yamazaki H, Ohbu M, Watanabe M and Yokomori H: Over-the-counter drug induced autoimmune hepatitis. Intern Med 55: 1293-1297, 2016.

22. Rossi S and Navarro VJ: Herbs and liver injury: A clinical perspective. Clin Gastroenterol Hepatol 12: 1069-1076, 2014.

23. Kaneko R, Ohishi C, Kim M, Shiina M, Kusayanagi S, Ogawa M, Munakata K, Mizuno K and Sato Y: Two cases of food additive-induced severe liver damage associated with positive results on lymphocyte stimulation test and for antinuclear antibodies. Clin J Gastroenterol 5: 268-274, 2012.

24. Navarro VJ, Barnhart H, Bonkovsky HL, Davern T, Fontana RJ, Grant L, Reddy KR, Seeff LB, Serrano J, Sherker AH, et al: Liver injury from herbals and dietary supplements in the U.S. DrugInduced Liver Injury Network. Hepatology 60: 1399-1408, 2014

25. Chalasani N, Bonkovsky HL, Fontana R, Lee W, Stolz A, Talwalkar J, Reddy KR, Watkins PB, Navarro V, Barnhart H, et al; United States Drug Induced Liver Injury Network: United states drug induced liver injury network. Features and outcomes of 899 patients with drug-induced liver injury: The DILIN prospective study. Gastroenterology 148: 1340-52.e7, 2015.

26. Ortega-Alonso A, Stephens C, Lucena MI and Andrade RJ: Case characterization, clinical features and risk factors in druginduced liver injury. Int J Mol Sci 17: 714, 2016.

27. Chen M, Suzuki A, Borlak J, Andrade RJ and Lucena MI: Drug-induced liver injury: Interactions between drug properties and host factors. J Hepatol 63: 503-514, 2015.

28. Björnsson ES: Hepatotoxicity by drugs: The most common implicated agents. Int J Mol Sci 17: 224, 2016.

29. Haque T, Sasatomi E and Hayashi PH: Drug-induced liver injury: Pattern recognition and future directions. Gut Liver 10: 27-36, 2016.

30. Devarbhavi H: Antituberculous drug-induced liver injury: Current perspective. Trop Gastroenterol 32: 167-174, 2011.

31. Saukkonen JJ, Cohn DL, Jasmer RM, Schenker S, Jereb JA, Nolan CM, Peloquin CA, Gordin FM, Nunes D, Strader DB, et al; ATS (American Thoracic Society) hepatotoxicity of antituberculosis therapy subcommittee: An official ATS statement: Hepatotoxicity of antituberculosis therapy. Am J Respir Crit Care Med 174: 935-952, 2006.

32. Watkins PB and Seeff LB: Drug-induced liver injury: Summary of a single topic clinical research conference. Hepatology 43: 618-631, 2006.

33. Foufelle F and Fromenty B: Role of endoplasmic reticulum stress in drug-induced toxicity. Pharmacol Res Perspect 4: e00211, 2016.

34. Herbert TP and Laybutt DR: A Reevaluation of the role of the unfolded protein response in islet dysfunction: Maladaptation or a failure to adapt? Diabetes 65: 1472-1480, 2016.

35. Su HY, Waldron RT, Gong R, Ramanujan VK, Pandol SJ and Lugea A: The unfolded protein response plays a predominant homeostatic role in response to mitochondrial stress in pancreatic stellate cells. PLoS One 11: e0148999, 2016.

36. Oñate M, Catenaccio A, Martínez G, Armentano D, Parsons G, Kerr B, Hetz C and Court FA: Activation of the unfolded protein response promotes axonal regeneration after peripheral nerve injury. Sci Rep 6: 21709, 2016. 
37. Bensellam M, Maxwell EL, Chan JY, Luzuriaga J, West PK, Jonas JC, Gunton JE and Laybutt DR: Hypoxia reduces ER-to-Golgi protein trafficking and increases cell death by inhibiting the adaptive unfolded protein response in mouse beta cells. Diabetologia 59: 1492-1502, 2016.

38. Chan JY, Luzuriaga J, Bensellam M, Biden TJ and Laybutt DR: Failure of the adaptive unfolded protein response in islets of obese mice is linked with abnormalities in $\beta$-cell gene expression and progression to diabetes. Diabetes 62: 1557-1568, 2013.

39. Sykes EK, Mactier S and Christopherson R: Melanoma and the unfolded protein response. Cancers (Basel) 8: E30, 2016.

40. Luo S, Mao C, Lee B and Lee AS: GRP78/BiP is required for cell proliferation and protecting the inner cell mass from apoptosis during early mouse embryonic development. Mol Cell Biol 26 5688-5697, 2006.

41. Xiong Z, Jiang R, Li X, Liu Y and Guo F: Different roles of GRP78 on cell proliferation and apoptosis in cartilage development. Int J Mol Sci 16: 21153-21176, 2015.

42. Ye R, Jung DY, Jun JY, Li J, Luo S, Ko HJ, Kim JK and Lee AS: Grp78 heterozygosity promotes adaptive unfolded protein response and attenuates diet-induced obesity and insulin resistance. Diabetes 59: 6-16, 2010.

43. Fusakio ME, Willy JA, Wang Y, Mirek ET, Al Baghdadi RJ, Adams CM, Anthony TG and Wek RC: Transcription factor ATF4 directs basal and stress-induced gene expression in the unfolded protein response and cholesterol metabolism in the liver. Mol Biol Cell 27: 1536-1551, 2016.

44. Aarti I, Rajesh K and Ramaiah KV: Phosphorylation of eIF2 alpha in Sf9 cells: A stress, survival and suicidal signal. Apoptosis 15: 679-692, 2010

45. Baird TD and Wek RC: Eukaryotic initiation factor 2 phosphorylation and translational control in metabolism. Adv Nutr 3 : 307-321, 2012.

46. Nagiah S, Phulukdaree A and Chuturgoon AA: Lon protease and eiF $2 \alpha$ are involved in acute, but not prolonged, antiretroviral induced stress response in HepG2 cells. Chem Biol Interact 252: 82-86, 2016.

47. Muaddi H, Majumder M, Peidis P, Papadakis AI, Holcik M, Scheuner D, Kaufman RJ, Hatzoglou M and Koromilas AE: Phosphorylation of eIF2 $\alpha$ at serine 51 is an important determinant of cell survival and adaptation to glucose deficiency. Mol Biol Cell 21: 3220-3231, 2010.
48. Lee SK and Kim YS: Phosphorylation of eIF2 $\alpha$ attenuates statin-induced apoptosis by inhibiting the stabilization and translocation of p53 to the mitochondria. Int J Oncol 42: 810-816, 2013.

49. Peidis P, Papadakis AI, Muaddi H, Richard S and Koromilas AE: Doxorubicin bypasses the cytoprotective effects of eIF $2 \alpha$ phosphorylation and promotes PKR-mediated cell death. Cell Death Differ 18: 145-154, 2011.

50. Yuan T,Luo BL, Wei TH,Zhang L, He BM and Niu RC: Salubrinal protects against cigarette smoke extract-induced HBEpC apoptosis likely via regulating the activity of PERK-eIF $2 \alpha$ signaling pathway. Arch Med Res 43: 522-529, 2012.

51. Wang H, Wang X, Ke ZJ, Comer AL, Xu M, Frank JA, Zhang Z, Shi X and Luo J: Tunicamycin-induced unfolded protein response in the developing mouse brain. Toxicol Appl Pharmacol 283: $157-167,2015$.

52. Zamarbide M, Martinez-Pinilla E, Ricobaraza A, Aragón T, Franco R and Pérez-Mediavilla A: Phenyl acyl acids attenuate the unfolded protein response in tunicamycin-treated neuroblastoma cells. PLoS One 8: e71082, 2013.

53. Fan L, Sun G, Ma T, Zhong F, Lei Y, Li X and Wei W: Melatonin reverses tunicamycin-induced endoplasmic reticulum stress in human hepatocellular carcinoma cells and improves cytotoxic response to doxorubicin by increasing $\mathrm{CHOP}$ and decreasing survivin. J Pineal Res 55: 184-194, 2013.

54. Quan X, Wang J, Liang C, Zheng H and Zhang L: Melatonin inhibits tunicamycin-induced endoplasmic reticulum stress and insulin resistance in skeletal muscle cells. Biochem Biophys Res Commun 463: 1102-1107, 2015.

55. Liu SH, Yang CC, Chan DC, Wu CT, Chen LP, Huang JW, Hung KY and Chiang CK: Chemical chaperon 4-phenylbutyrate protects against the endoplasmic reticulum stress-mediated renal fibrosis in vivo and in vitro. Oncotarget 7: 22116-22127, 2016.

56. Vilatoba M, Eckstein C, Bilbao G, Smyth CA, Jenkins S, Thompson JA, Eckhoff DE and Contreras JL: Sodium 4-phenylbutyrate protects against liver ischemia reperfusion injury by inhibition of endoplasmic reticulum-stress mediated apoptosis. Surgery 138: 342-351, 2005.

57. Yan S, Zhang H, Wang J, Zheng F and Dai J: Perfluorooctanoic acid exposure induces endoplasmic reticulum stress in the liver and its effects are ameliorated by 4-phenylbutyrate. Free Radic Biol Med 87: 300-311, 2015. 